\title{
PITTSBURGHESE SHIRTS: COMMODIFICATION AND THE ENREGISTERMENT OF AN URBAN DIALEGT
}

\author{
BARBARA JOHNSTONE \\ Carnegie Mellon University
}

\begin{abstract}
This article considers a type of material artifact that circulates ideas about regional speech in the United States: T-shirts bearing words and phrases thought to be unique to Pittsburgh, Pennsylvania. I argue that Pittsburghese shirts, seen for themselves and in the context of their production, distribution, and consumption, are part of a process leading to the creation and focusing of the idea that there is a Pittsburgh dialect. To describe how particular locally hearable forms have become linked with the city, I invoke Asif Agha's concept of "enregisterment." To understand why this has happened at the time and in the way it has, I draw on Arjun Appadurai's model of the "commodity situation." I suggest that Pittsburghese shirts contribute to dialect enregisterment in at least four ways: they put local speech on display, they imbue local speech with value, they standardize local speech, and they link local speech with particular social meanings.
\end{abstract}

I

N THE COURSE Of SOciolinguistic InTERviews in the Pittsburgh area, I and my fellow field-workers asked our interviewees what they knew about "Pittsburghese," the local name for what is thought to be a distinctive Pittsburgh dialect. Their answers were sometimes supported by material artifacts bearing representations of "Pittsburghese." When I asked for examples of local peculiarities of speech, one interviewee produced a coffee mug decorated with "Pittsburghese" words. Another interviewee, when asked if he had ever heard of the dialect, opened a bag he had brought along and dramatically produced a white T-shirt with letters and images in black and gold. The front of the shirt depicted the city's skyline with words like pop, redd up, keller, hans, and sammich superimposed on it. On the back was a dictionary-like list of words and phrases with definitions and sample sentences. "This," he told us, holding up the shirt, "is Pittsburghese." In another interview, Jenn R., a speaker of the local dialect in Pittsburgh, responded: ${ }^{1}$

Oh yes. I mean, there's that store over on the Southside, in Station Square that has the Pittsburghese shirts. In fact, I remember when my friend Karen moved out of

American Speech, Vol. 84, No. 2, Summer 2009 DOI 10.1215/ooo31283-2009-O13

Copyright 2009 by the American Dialect Society 


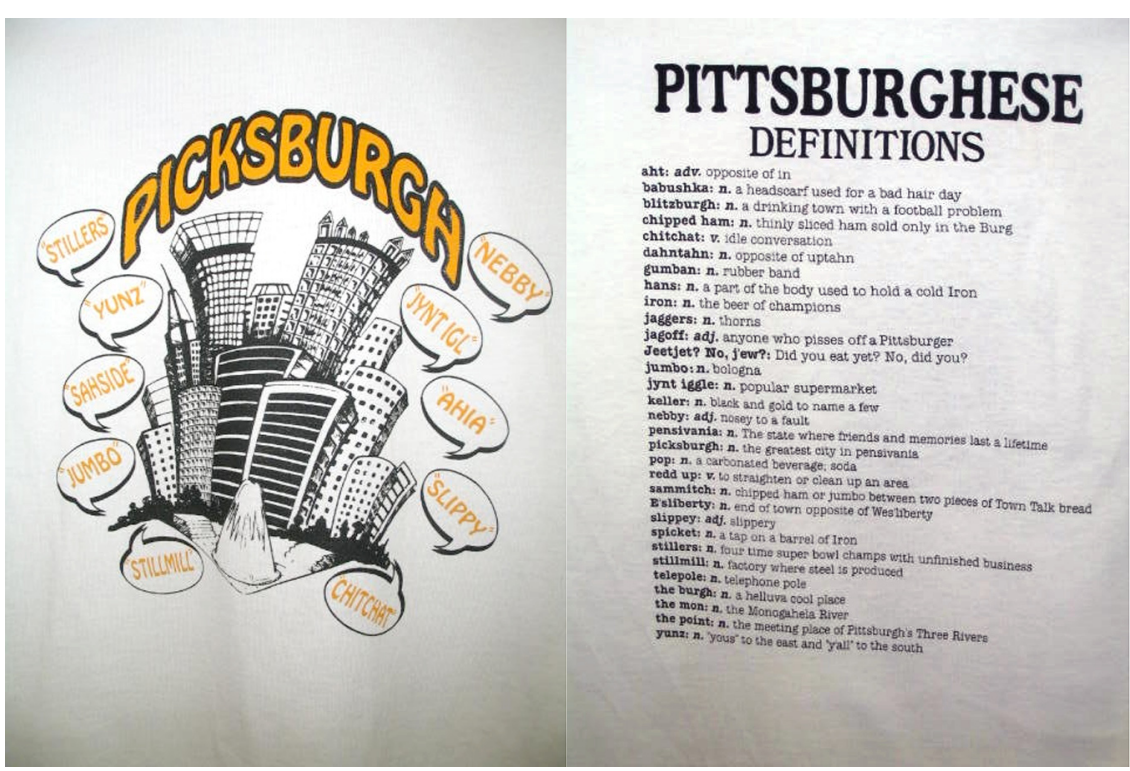

state, with- her husband's job took them out of state and to many other states, I remember sending her a couple Pittsburghese shirts for them.

Asked whether she's familiar with the dialect, Jenn talks about the T-shirt: "Oh yes, I mean there's that store ... that has the Pittsburghese shirts."

As in the interview with Jenn R., "Pittsburghese shirts" were often among the first things mentioned when people talked to us about local speech in Pittsburgh. These shirts, for sale at sidewalk markets, in souvenir shops, and online, often look like the one we were shown by the man described above. Figure 1 shows the front and back of a typical Pittsburghese shirt.

The shirts are almost always either white, black, or a yellow-orange color thought of locally as "gold," with printing in white, black, and/or gold. The front typically depicts the cityscape and includes the word "Pittsburghese" (sometimes "Pixburghese") together with a scattering of words spelled phonetically to represent local pronunciation (dahntahn 'downtown', worsh 'wash', jynt iggle 'Giant Eagle' supermarkets), vocabulary (gumban 'rubber band', redd up 'tidy up', slippy or slippey 'slippery'), and sometimes syntax (needs washed 'needs to be washed'). On the back there is typically a dictionary-like alphabetical list. Newer designs are often simpler, involving a single black word or phrase on the front of a white shirt: YNZ (yinz 'you, pl.'), I'm surrounded by jagoffs! 'jerks, irritating people'. ${ }^{2}$ 
As is suggested by the fact that all but a handful of over 100 interviewees had heard of "Pittsburghese" and could talk about it, there is a very high level of dialect awareness in Pittsburgh. This is true even among people who do not themselves have strong local accents, including outsiders who live in the area and many local African Americans. ${ }^{3}$ Unelicited, naturally occurring evidence of dialect awareness is provided by the ubiquity and variety of items representing "Pittsburghese" that are for sale in the city: coffee mugs, shot glasses, beer steins, refrigerator magnets, postcards, talking dolls, bumper stickers, dog clothing, shirts, and hats. The most prevalent-in that it is among the oldest and most widely available and in that it displays the most variety and reflects changes fastest-is the Pittsburghese shirt.

In this article I argue that Pittsburghese shirts are not simply evidence of dialect awareness, however. Rather, I claim, these T-shirts, seen for themselves and in the context of their production, distribution, and consumption, are part of a process leading to the creation and focusing of the idea that there is a Pittsburgh dialect in the first place. To make this argument, I invoke the concept of "enregisterment" (Agha 2003, 2007), the processes by which particular linguistic forms become linked with "social" meaning. In Pittsburgh a set of locally hearable forms have becomes linked with an imagined (in Anderson's 1991 sense) "dialect" called "Pittsburghese." To understand why this has happened at the time and in the way it has and why T-shirts have become part of the process, I draw on the literature from critical discourse analysis, anthropological linguistics, and cultural anthropology about globalization and commodification and on eight years of ethnographic participant-observation, over 100 sociolinguistic interviews, and several collections of texts and other artifacts (including T-shirts collected between 1997 and 2008) that represent local speech in Pittsburgh. I show that a set of material, ideological, and historical facts have come together to make Pittsburgh speech into a commodity that can add value to items like T-shirts. Finally, I suggest that Pittsburghese shirts contribute to dialect enregisterment in at least four ways: they put local speech on display; they imbue local speech with value; they standardize local speech; and they link local speech with particular social meanings.

\section{ENREGISTERMENT}

Although linguistic variation is audible to someone listening for it, a dialect is not. What linguists and laypeople alike encounter in lived experience are particular speakers, writers, or signers, saying particular things in particular ways. The variation between one speaker and another, or between the same person's speech in one situation as opposed to another, is often unnoticeable 
to a particular hearer. In order to become noticeable, a particular variant must be linked with an ideological scheme that can be used to evaluate it in contrast to another variant. For example, if, according to the ideological scheme that comes into play, women are expected to act differently than men, particular features may come to sound gendered (Ochs 1992). Alternatively, the scheme to which a hearer orients may be one that links variation with class, carefulness, correctness, place, or any other framework in terms of which people position one another socially, each associated with a set of stereotypical personas.

Ideas about how linguistic variants are associated with identities may be quite idiosyncratic. (A particular way of saying a particular word may remind you of your grandfather.) However, some of these linkages can come to be shared via "metapragmatic" practices (Silverstein 1993) by which people indicate to one another what particular forms mean. (Someone may point out that your grandfather sounded like a Philadelphian, upon which you are able to transform the idiosyncratic linkage of a form with an individual's personal identity to a more widely shared linkage of the form with a regional dialect.) Form-meaning links can be suggested directly, in explicit talk about talk ("People who say 'dahntahn' sound ignorant"), or indirectly, by associating forms with social stereotypes in other ways (Johnstone forthcoming). Once it comes to be interpreted and evaluated with reference to an ideological scheme, a linguistic form has been "enregistered." A form that is enregistered is one that is linked with a way of speaking or "register" associated with a personal or social identity.

The same feature can be enregistered in multiple ways. For example, in the history of English, alveolar (ing) (the pronunciation of the morpheme -ing as [In]) has been associated with both upper-class and lower-class speech. In Pittsburgh, the same features that are in some situations, by some people, associated with uneducated, sloppy, or working-class speech can, in other situations and sometimes by other people, be associated with the city's identity, with local pride and authenticity. Over time, the indexical linkages between linguistic forms and social meanings can evolve so that one ideological scheme used to link forms and meanings can be replaced by another. By virtue of a variety of discursive and metadiscursive activities, a set of features associated with an accent can come to be represented collectively in the public imagination as a stable register (in the case in question in this paper, the sort of place-linked register that is typically called a "dialect") and maintained across time via practices that reiterate and reinforce the evaluation of the register and its link to the social identity associated with a particular type of persona (the authentic Pittsburgher, in this case). 


\section{COMMODIFICATION}

Although the term "commodification" is used in a variety of ways, sometimes to refer to any reification of a social process, a narrower and more literal conceptualization captures the process represented by Pittsburghese shirts. Borrowing Fairclough's (1992, 207) definition, I conceptualize commodification as "the process whereby social domains and institutions, whose concern is not producing commodities in the narrower economic sense of goods for sale, come nevertheless to be organized and conceptualized in terms of commodity production, distribution, and consumption." A linguistic variety or a set of varieties is commodified when it is available for purchase and people will pay for it. For example, Hall (1995) explores the commodification of an intimate register of talk by telephone sex workers who are paid for intimacy. Cameron (2000) discusses the commodification not only of speech styles but of particular scripted utterances in new-economy jobs like telephone marketing, consumer service, and opinion polling, where highly standardized speech has economic value and people are paid to produce it. Gaudio (2003) explores how conversation is commodified by a coffeehouse chain, and Bucholtz (1999, 2008) shows how linguistic styles can involve ways of talking associated with material goods. English has become a valuable commodity world-wide, and other languages more locally (Tan and Rubdy 2008). Heller (2003) shows how French-English bilingualism, once associated with Francophone Canadian identity but stigmatized on the economic market, has come to be a valuable commodity in the call-center sector, as call centers locate where bilinguals can be hired.

What people are buying when they buy a Pittsburghese shirt is not only an item of clothing but also the words and images on it. A men's plain white Hanes T-shirt is available for retail purchase for as little as \$2.19 but will sell for $\$ 5$.oo or $\$ 8$.oo with Pittsburghese printed on it. What has happened, locally and in popular culture at large, to enable Pittsburgh speech to add value to a shirt in this way? Appadurai's (1986) description of the "commodity situation" is a useful heuristic for exploring the conditions and processes that have led to the viability of Pittsburghese shirts.

According to Appadurai, the "commodity situation in the social life of any 'thing' [can] be defined as the situation in which its exchangeability (past, present, or future) for some other thing is its socially relevant feature." In order to enter into a commodity situation, a "thing" (in our case, the imagined dialect people call "Pittsburghese") must, historically, be in a "commodity phase," it must be a potential "commodity candidate," and it must be in a viable "commodity context" $\left(13^{-15}\right)$. In other words, to understand how and 
why Pittsburghese has become a commodity bought and sold in the form of T-shirts, we need to answer these questions:

1. Commodity phase: When and how did local speech in Pittsburgh acquire the potential for commodification? What set of ideas about local speech had to be in place before people could begin to think of it as having economic value in this way? Answering these questions requires taking a historical perspective on the indexical meanings of Pittsburgh linguistic forms.

2. Commodity candidacy: What makes something like local speech a potential commodity? What is the larger cultural framework in which it makes sense to people to buy and sell Pittsburghese? Answering these questions requires thinking about more widely circulating ideas about place, identity, and authenticity that shape how vernacular practices like regional speech are evaluated.

3. Commodity context: In what ideological and material contexts can local speech be a viable commodity? Answering this question requires taking a close look at the economics of T-shirt sales and the ideas about T-shirts as a medium of communication that encourage people to produce and purchase Pittsburghese shirts.

In what follows, I discuss each of these issues in turn. Since each of these sections could itself be an article, these discussions are necessarily brief. Rather than touching on every element of the context that makes Pittsburghese shirts possible, I focus on a few key elements in each category.

commodity PHASE. When is Pittsburgh speech in a commodity phase? In other words, when does local speech become a potential commodity? To answer this question, I turn again to the process by which speech features can become enregistered in multiple ways that change over time. One way of thinking about this process is in terms of "orders of indexicality" (Silverstein 2003). According to Silverstein, linguistic features that are correlated with demographic facts about people (adapting Silverstein's more abstract terminology to an actual historical context, I call these first-order indexicals) can come to do social work, as people enregister these features in terms of some set of ideas about the people who use them. A group of features that have been enregistered in terms of an ideological schema that divides languages into neatly bounded sets of varieties, some of which can be mapped onto places, can come to be thought of as a "dialect." This is the ideological schema that typically shapes dialectologists' (and to some extent sociolinguists') experience with variation. But what may start out sounding like a dialect to linguists may not start out sounding that way to local laypeople, and even once they come to hear a particular set of local features as a regional dialect, the indexical meaning of using the dialect can vary and change. 
In Pittsburgh, local forms were at first only correlated with demographic facts about their users. Because there was no metapragmatic activity calling attention to the first-order correlation, the forms had no indexical meaning. Only when alternative forms began to be heard did some Pittsburgh forms become hearable, by contrast with the alternatives. It should be noted that the set of forms that have become hearable in Pittsburgh includes many forms also heard outside of Pittsburgh and does not include some forms that are heard in Pittsburgh. With the exception of the monophthongization of law/, usually represented on T-shirts as <ah > in words like "dahntahn," all occur elsewhere in western and central Pennsylvania, along the Ohio River valley, or in Appalachia. Of interest in this article is not which elements of "Pittsburghese" a linguist would associate with Pittsburgh as opposed to other places, but why and how a particular set of features comes to be associated with Pittsburgh in the popular imagination. In other words, the set of forms associated with "Pittsburghese" in the local imagination is not the same as the set of forms a linguist, operating with a different set of assumptions about language, class, and place, would identify with Pittsburgh speech.

Once they became hearable, features of local-sounding speech were first linked ideologically with working-class identity, incorrectness, and/or lack of education. ${ }^{4}$ These are the "second-order" indexical meanings of the dialect. Gradually, however, the set of features enregistered as "Pittsburghese" and the indexical meaning of using them have started to shift, so that now many people hear a slightly different subset of features of local speech as expressing local identity and some can use it to project localness. These are "third-order" indexical links. Table 1 sketches this process.

Pittsburgh speech entered a commodity phase only when local forms were socially meaningful at the third-order level, that is, when they were no longer linked exclusively with class or correctness but also (or, for some people, instead) with local identity. It is at this stage that a Pittsburgh word or phrase can come to evoke local pride or nostalgia, even among people who do not identify themselves as working-class or as speakers of a nonstandard variety. While the earlier (and, for some people, still exclusively) more stigmatized meanings of local forms still resonate, so that a Pittsburghese shirt may still call to mind working-class pride and disregard for correctness, this link is now indirect, mediated by the association of local forms with authentic localness.

As we have shown in more detail elsewhere (Johnstone, Andrus, and Danielson 2006), moves from first- to second-order and from second- to third-order indexicality of local speech forms have been enabled by social and geographical mobility. When Pittsburgh women began to get jobs as secretaries and receptionists, they came into contact with other social classes 
TABLE 1

Indexical Change in Pittsburgh

Silverstein (2003)

“ $n$-th-Order Indexical”: A feature whose use can be correlated with a sociodemographic identity (e.g., region or class) or a semantic function (e.g., number-marking).

" $n+1$-th-Order Indexical": An $n$-th order indexical feature that has been assigned "an ethno-metapragmatically driven native interpretation" (212), i.e., a meaning in terms of one or more native ideologies (the idea that certain people speak more correctly than others, for example).

“ $(n+1)+1$-th-order indexical”: An indexical phenomenon at order $n+1$ can come to have another, $(n+1)+1$-th-order, indexical meaning when a subset of its features come to be perceived as meaningful according to another ideological schema.
In Pittsburgh

First-Order Indexicality: The frequency of regional variants in a person's speech can be correlated with whether he/she is from southwestern Penn. (especially from Pittsburgh), working-class, and/or male.

Second-Order Indexicality: Regional features become available for social work; speakers start to notice and attribute meaning to regional variants and shift styles in their own speech. The meaning of these forms is shaped, for many, by ideologies about class and correctness.

Third-Order Indexicality: People who notice the existence of second-order stylistic variation in Pittsburghers' speech link the regional variants they are most likely to hear with Pittsburgh identity, drawing on the idea that places and dialects are essentially linked.

and their ways of talking and had to learn to vary their speech in order to sound more correct and careful, or, alternatively, more like their peers. When Pittsburghers began to travel, in the military and on vacation, and came into contact with people from other places who sounded different and noticed that the Pittsburghers sounded different to them, they began to connect local speech with place and identity. Mobility has thus been perhaps the crucial factor in putting Pittsburgh speech into a commodity phase.

COMMODITY CANDIDACY. One of the many intersecting sets of ideas that make local speech a potential commodity is the ideology about language, place, and tradition that underlies what Bendix (1988) calls "folklorism." This is the idea, which originates in nineteenth-century Romanticism and continues to circulate today, that old, vernacular practices and artifacts are the most authentic. According to the ideology of folklorism, "authentic" folk ways are untainted, desirable in a way that newer practices are not, even if newer 
ways are more practical. Ideas like these lead people to want to preserve old things and old ways of doing things even if-or even to show that-they do not do things that way themselves. In Pittsburgh, being able to cite the older form of a local word can be a useful way of claiming expertise about local speech (Johnstone 2007).

According to the ideology of folklorism, cultural authenticity is also linked with connectedness to place. This is because older social practices last longer in isolated places, where it is less likely that new practices will be imported. People and practices that have never moved, or that have generations of rootedness in a particular geographic area, are, according to this set of ideas, better and more authentic than others. When this ideological scheme is in play, Appalachian folk-songs collected in remote valleys trump contemporary or even classical forms, Texas roper boots and broad-brimmed hats trump contemporary clothing, "Downeaster" accents from Maine trump more regional or national varieties. In Pittsburgh, the display of local speech is sometimes part and parcel of the display of other elements of local cultural heritage, like steelworkers' hard hats, plaques and signs commemorating local people and historical moments, buildings where memorable events occurred, and the like. The Pittsburgh historical museum has at times had a small informational poster about Pittsburgh speech on display, and a film and a museum exhibit on the theme of "Pittsburgh A to Z" both featured the pronoun yinz ('you, pl.'; a form of you ones) to fill the slot for Y. Knowing what local linguistic forms mean is sometimes explicitly linked with Pittsburgh authenticity, as in the T-shirt in figure 2.

commodity context. When the right historical and ideological factors are in place, economic and technical factors must also line up in such a way as to make Pittsburghese shirts viable as a commodity. First, it must make sense in the context of local resources and practices to sell and buy T-shirts with words and images printed on them. People must know by whom and why such shirts can be worn, and the shirts must seem affordable. As Miller (2002) points out in a study of T-shirts produced by fans of the rock band Phish, there is a tradition in the U.S. and elsewhere of playful T-shirts, often featuring borrowed and recontextualized images. Such shirts are purchased and worn because of their "badging" function (Symes 1987; Kelly 2003). People who see Pittsburghese shirts for sale tend, in other words, to know how to consume them, both in the sense of how to interpret them and in the sense of who might wear them and in what contexts.

Second, elements of the shirts' design must be available. The designers of Pittsburghese shirts draw heavily for the shirts' content on Internet lists of Pittsburghese words, such as http://www.pittsburghese.com. The shirt 


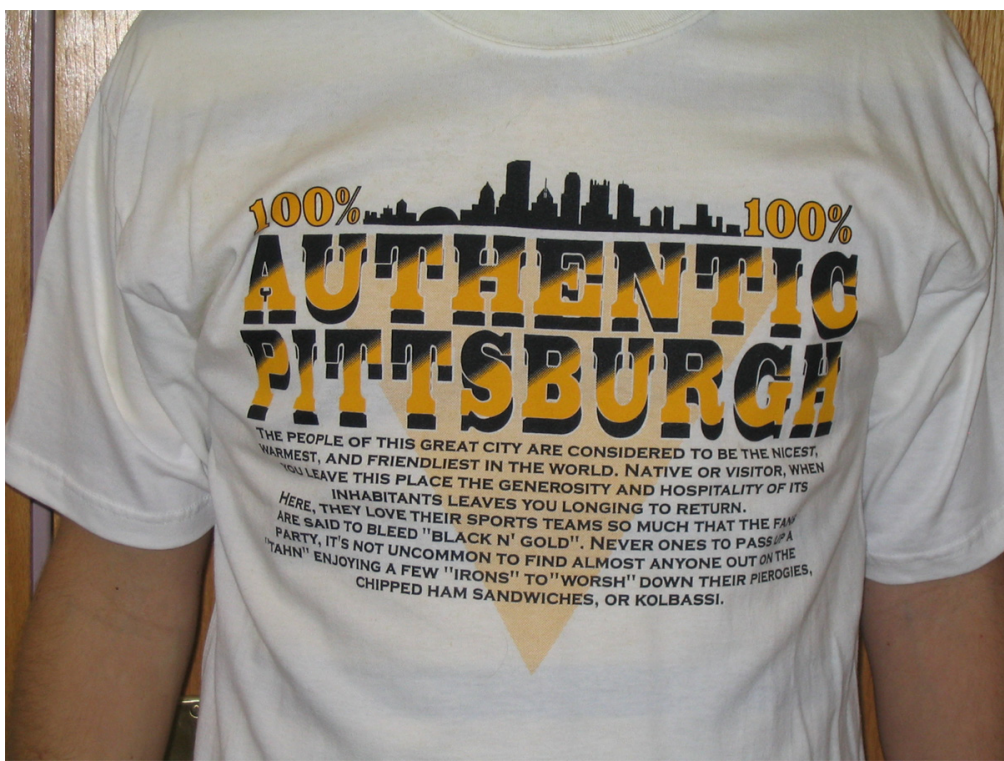

NOTE: The final sentence reads, "It's not uncommon to find almost anyone out on the 'tahn' enjoying a few 'irons' to 'worsh' down their pierogies, chipped ham sandwiches, or kolbassi."

in figure 3 borrows a well-known phrase, "I'm surrounded by idiots," and reworks it with a local word, jagoff.

Ideas for the shirts' visual design are also borrowed and reused. Black and gold, the colors of the city's sports teams and the city shield and flag, are almost compulsory for any item alluding to local identity. Images of the downtown cityscape have been featured on Pittsburghese shirts since they were first produced. Other elements of visual design are also borrowed. During the 1990s, automobile bumper-stickers that identify vacation spots in a design borrowed from European country-identification stickers became common in the Pittsburgh area and elsewhere in the United States. For example, OBX, in black on white and enclosed in a black-bordered oval, means the Outer Banks, HHI, Hilton Head Island-both popular beach destinations for Pittsburghers. The T-shirt in figure 4 borrows this design and reworks it with a designation based not on a place-name abbreviation but on the word $y i n z$, which is thought to be an exclusively Pittsburghese form. 
FIGURE 3

"I'm Surrounded by Jagoffs" Shirt

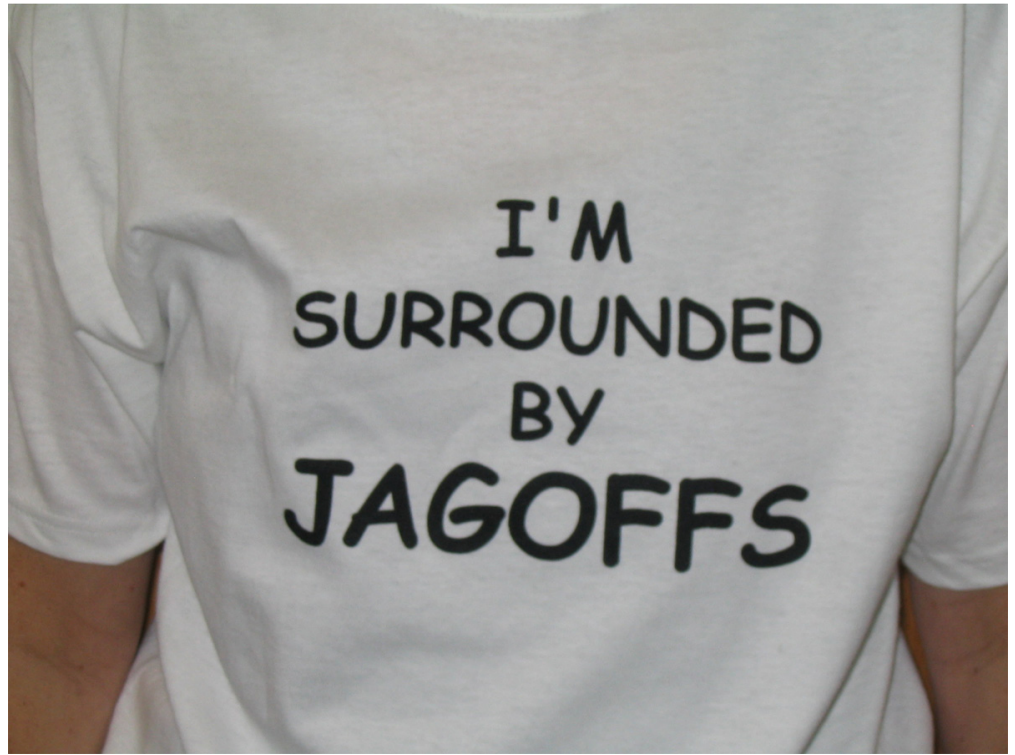

FigurE 4

"YNZ Pittsburgh" Shirt

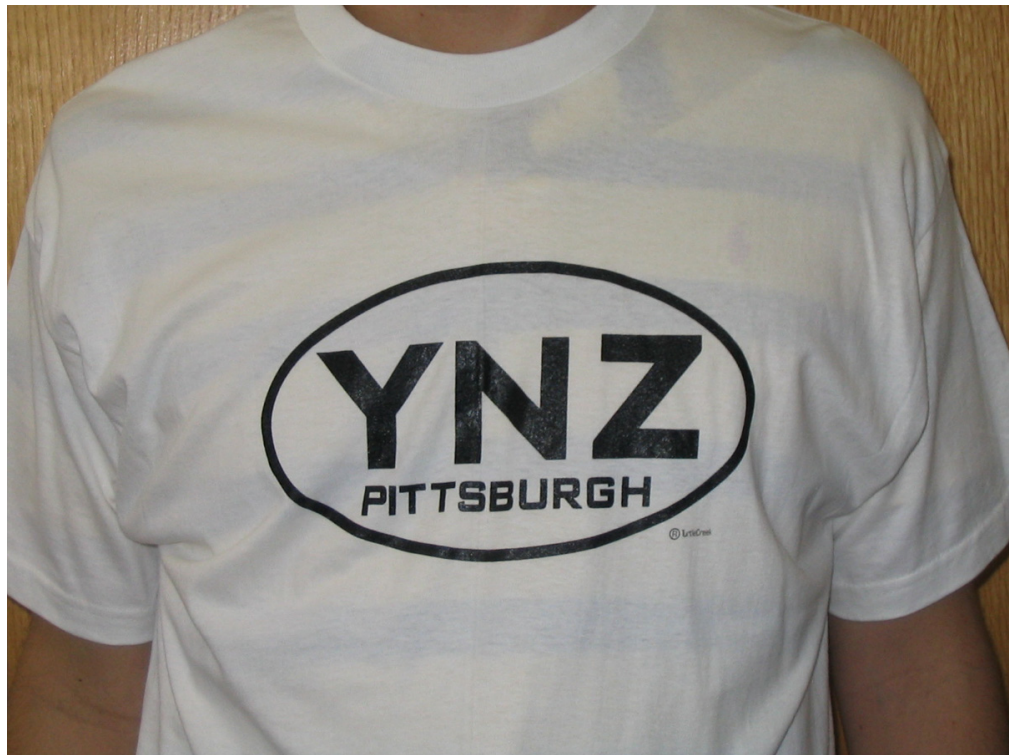


Third, producing and selling Pittsburghese shirts must be economically feasible. The availability of wholesale T-shirts and sweatshirts at low cost, together with inexpensive reproduction technology that is available locally, makes the shirts relatively disposable, so people are willing to purchase them without much forethought. According to the website of Berda CompuGraphix (http://www.berda.com), a T-shirt wholesaler and printer located near Pittsburgh, a white, $100 \%$ cotton, heavyweight or $5^{\circ} / 5^{\circ} \%$ cotton/poly blend T-shirt, including one-color printing in one location, wholesales for \$3.29 per shirt if $5^{\text {oo }}$ shirts are purchased. Selling such a shirt for as little as $\$ 5.00$ represents a $50 \%$ markup. Gold shirts with black printing are $\$ 5.29$

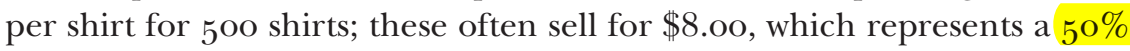
markup. Dealers' overhead costs are low, since the shirts can be produced nearby and are often sold on the street. In sum, it makes economic sense both to sell Pittsburghese shirts and to buy them.

\section{PITTSBURGHESE SHIRTS AND THE ENREGISTERMENT OF PITTSBURGH SPEECH}

Pittsburgh shirts both require and contribute to the enregisterment of local speech forms as a dialect. Enregisterment is a precondition for Pittsburghese shirts for two reasons. First, the shirts appeal to people who are able to hear Pittsburgh speech as different from other varieties and who link Pittsburgh speech not with working-class or incorrect speech as much as with authentic local identity. Second, they require already-available lists of linguistic forms identified with "Pittsburghese," and they require purchasers to be familiar with the practice of respelling words to make them sound local. As I have argued above, these conditions are met only when a set of local forms has been enregistered, and in particular only when their indexicality is third order.

But the third-order enregisterment of Pittsburgh speech is also an outcome of the production, distribution, and consumption of Pittsburghese shirts. This happens in several ways. For one thing, Pittsburghese shirts put local speech on display, on sidewalk display tables, in shops, and on bodies. (People actually wearing the shirts are not much in evidence in Pittsburgh, perhaps because there is little need for a person in Pittsburgh to "badge" the fact that he or she is a Pittsburgher. Pittsburghers living elsewhere and tourists who visit the city would have a greater use for the identity-badging afforded by the shirts.) Second, Pittsburghese shirts link local speech with social and economic value. T-shirts were once men's underwear, and many people who buy or wear them think they are appropriate only for casual- 
dress situations. Pittsburghese shirts are also relatively inexpensive. This both mirrors and suggests the idea that Pittsburgh speech has limited value but may be appropriate in some contexts.

Third, Pittsburghese shirts help standardize Pittsburghese, the imagined dialect. This is by virtue of their intertextuality with one another and with representations of Pittsburgh speech in other media, such as online lists and McCool's (1982) well-known folk dictionary. A comparison of one T-shirt from the late 199 os with the McCool dictionary makes this clear. Of the 32 words on the shirt, 26 were also in the folk dictionary, and 20 of these were spelled the same way on the shirt as in the book. When asked, during fieldwork, where they get their ideas, T-shirt vendors sometimes refer to "lists on the Internet." This degree of intertextuality is made possible in large part by the fact that Pittsburghese shirts are bought and sold in a grassroots, often literally person-on-the-street market that is not quite legitimate, if not quite illegitimate. Trademarking is rare, and designers and vendors are unlikely to sue one another for copying their ideas, word lists, or designs. ${ }^{5}$

Finally, Pittsburghese shirts, and the economic practices in which they participate, lend specific meanings to local speech. They link dialect and place by juxtaposing local words on images of the city, sometimes directly, as

FIGURE 5

Linking Speech and Place on the Front of a T-Shirt

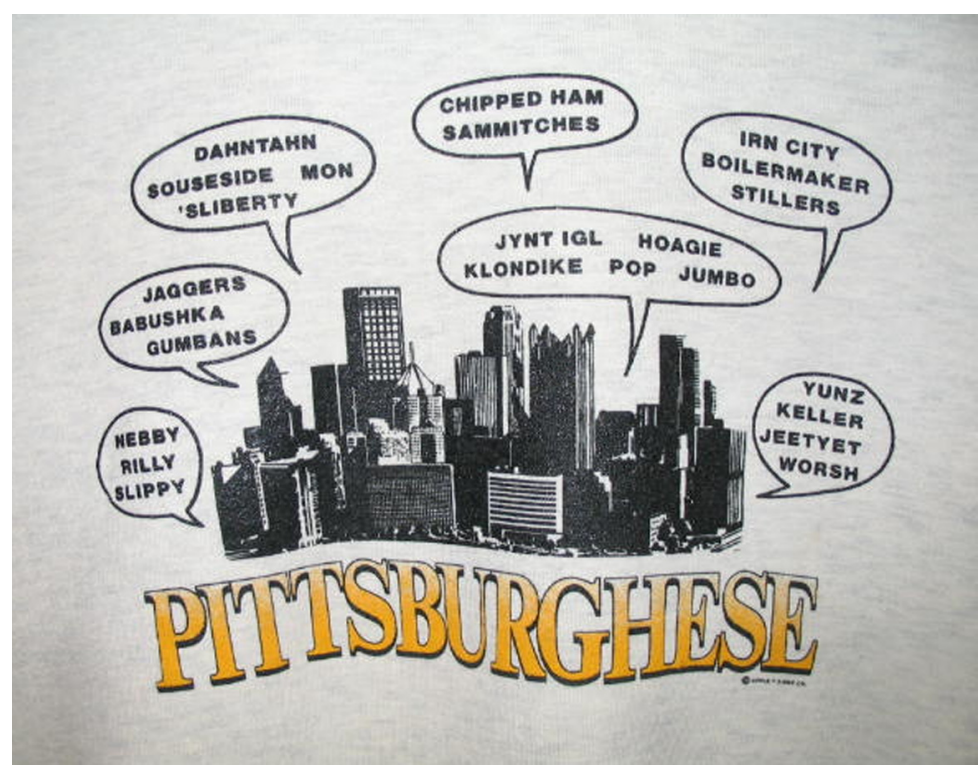


when local words are enclosed in speech balloons emanating from downtown windows (fig. 5 ; see also fig. 1 above).

As noted, their colors- the city's colors and those of the city's professional football, baseball, and hockey teams-also link the speech forms represented on the shirts with the city of Pittsburgh. The words that are included and the way words are defined on the backs of many of the shirts serves also to link the forms with local practices. Of the 31 items listed on the back of the shirt depicted in figure 1 above, 13 (arguably more if one includes more indirect allusions to the city) are forms that are explicitly linked with the Pittsburgh area, by virtue either of how they are defined or of their inclusion at all:

blitzburgh: $\mathbf{n}$. a drinking town with a football problem.

chipped ham: $\mathbf{n}$. thinly sliced ham sold only in the Burg

hans: n. a part of the body used to hold a cold Iron [Iron City is a Pittsburgh beer]

jagoff: $\mathbf{n}$. anyone who pisses off a Pittsburger [sic, Pittsburgher]

jynt iggle: $n$. a popular supermarket [Giant Eagle]

keller: $\mathbf{n}$. black and gold to name a few

picksburgh: $\mathbf{n}$. the greatest city in pensivania [Pennsylvania]

sammich: n. chipped ham or jumbo between two pieces of Town Talk bread [a local bakery]

spicket: $\mathbf{n}$. a tap on a barrel of Iron

stillers: $\mathbf{n}$. four time super bowl champs with unfinished business [Steelers, Pittsburgh's professional football team]

the burgh: $\mathbf{n}$. a helluva cool place

the mon: n. the Monogahela [sic, Monongahela] River

the point: $\mathbf{n}$. the meeting place of Pittsburgh's Three Rivers

The venues where Pittsburghese shirts are sold and the people who sell them reinforce the idea that local speech is casual and fun, linked with working-class mores, and in some cases even a bit shady. They are sold at airport newsstands and gift shops where tourists congregate and, probably more than anywhere else, in the wholesale market area called the Strip, now also a destination for "ethnic" foods sold in rundown but charming old buildings, a cafe where Italian can still be heard, and a number of more upscale kitchen-supply and home decorating stores. Pittsburghers of Italian heritage go to the Strip to shop for Italian breads, cheeses, and pastry, seafood for the traditional seven-fishes Christmas Eve dinner, and grapes for wine-making. There are also Greek, Arab, Asian, and Mexican shops. On the sidewalk, ready-made food, flowers, and a variety of other items such as cheap clothing and jewelry are sold from folding tables. On any Saturday, at least three T-shirt vendors open up or set up shop, one in an old, windowless storefront, one at a permanent wooden booth, and at least one at a folding table. Their 
location is thus associated experientially with traditional food ways and with an informal, leisurely way of shopping, for fun, in a somewhat grubby but comfortable environment. The Strip experience attracts tourists, reminds Pittsburghers of their heritage, and encourages impulse buying, which makes it an ideal site for the sale of Pittsburghese shirts.

The merchandise with which Pittsburghese shirts are juxtaposed on tables and hanging displays also reinforces its connection with local vernacular practices. Especially prominent are sports T-shirts, particularly ones celebrating the Pittsburgh Steelers. Some shirts combine Pittsburghese and sports imagery. Figure 6 shows three such shirts.

FIGURE 6

Pittsburgh Steelers/Pittsburghese Shirts

(rings and footballs on pedestals refer to the Steelers' Super Bowl championships)

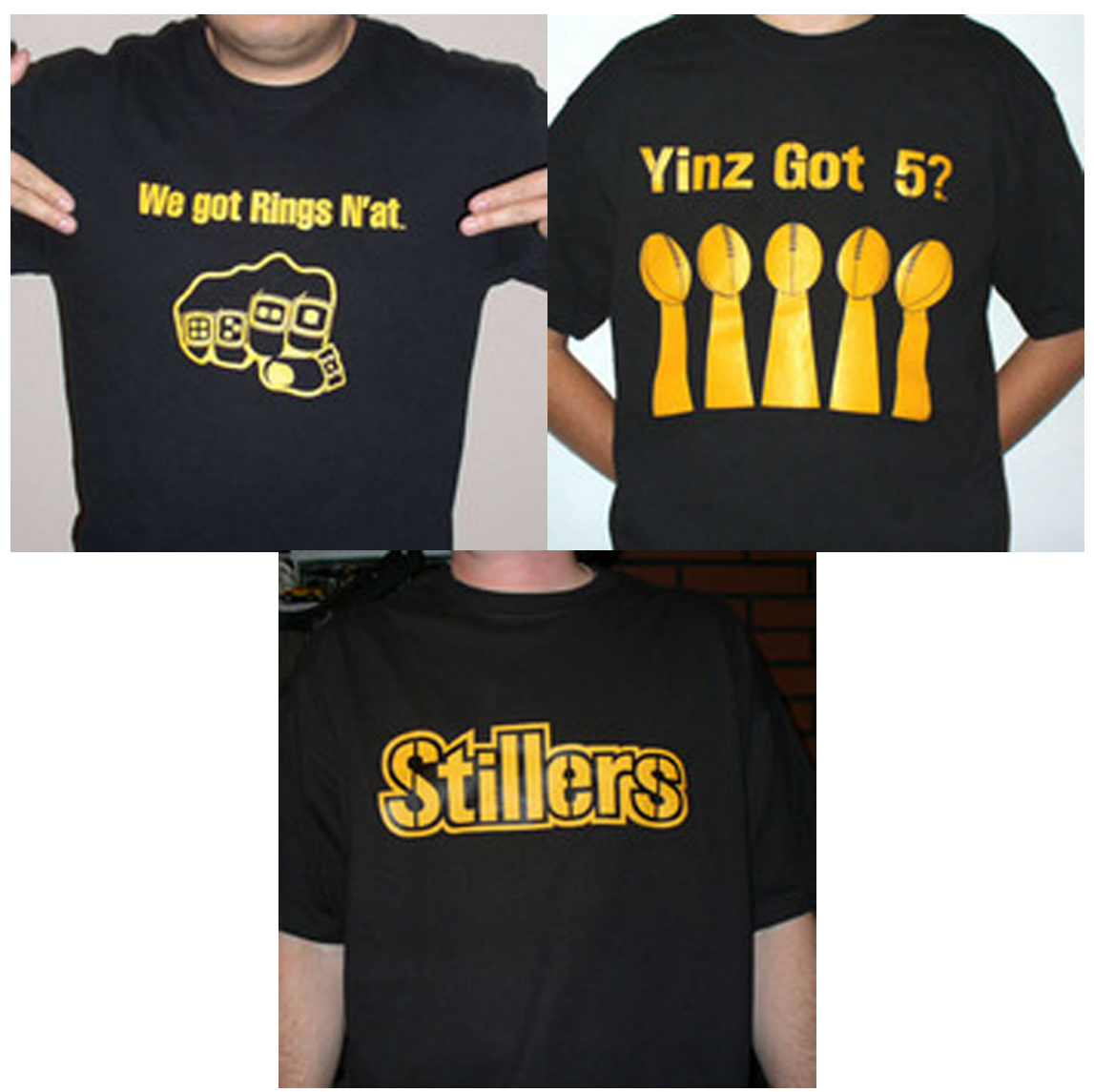


The first two refer to the team's fifth national championship victory in ways that include Pittsburghese forms (n'at, yinz); the third spells the team's name in a way that purports to represent how it is locally pronounced. In addition, Pittsburghese shirts are sometimes sold alongside shirts that disparage Cleveland, Pittsburgh's traditional sports rival.

\section{DISCUSSION}

The production and circulation of Pittsburghese shirts is one of the many ways in which many Pittsburghers, ex-Pittsburghers, and visitors come to share ideas about what Pittsburgh speech consists of and what it means. It is also evidence that this process has been going on for some time. Appadurai's heuristic provides a useful way of exploring the details about what makes Pittsburghese shirts viable. It would no doubt also be useful for exploring the circumstances under which other media for Pittsburghese have been produced, circulated, and consumed, although the details would be slightly different for coffee mugs or postcards than for T-shirts. As I hope to have shown, exploring the process of commodification of dialect also requires exploring the process of enregisterment of dialect. Dialect enregisterment is both a precondition for and an outcome of dialect commodification.

Exploring this process in detail is worthwhile not only because it is important for understanding the history of "Pittsburghese" and its impact on how Pittsburghers talk, but also because it is important for understanding the object of dialectologists' and sociolinguists' study in general. As we see in this and the accompanying articles, dialects do not exist in the world. Both we and the people we study create dialects as we use a variety of media and genres to exchange ideas about how people talk. These metapragmatic practices serve to link particular speech features with indexical meanings, by evoking ideological schemes in order to attribute certain social characteristics to people who use certain forms. Linguists' evolving ideas about language, place, and identity have led to a number of ways of demarcating dialect areas from one another, depending on whether the focus is on sounds (Labov, Ash, and Boberg 2005) or words (Carver 1987; Kretzschmar 2005). Laypeople's evolving ideas about language, place, and identity lead them to demarcate dialects from one another in different ways, ways that are often less systematic and seem less "objective." But the process is the same. We need, then, to be a more reflexive than we have been about where our own ideas about dialects come from and how they function. 


\section{NOTES}

The Pittsburgh Speech and Society Project was partially funded by U.S. National Science Foundation grants BCS-o41 7684 and BCS-0417657. I am also grateful to fellow field-workers Jennifer Andrus and Trista Pennington. Thanks to Joan Beal for organizing the session on "The Idea of a Dialect" at the Studies in the History of English (SHEL) 5 in 2007. Beal, Christine Mallinson, Kate Remlinger, and Joe Salmons all read an earlier draft and made useful suggestions.

1. I have edited this transcript to make it as readable as possible, since hesitations, back channeling, and the like are not germane to my analysis.

2. Jagoff derives from jag 'to poke, tease, annoy'. Jag in this sense occurs in other local words and phrases such as jaggerbush 'briar bush' and jag around 'fool around'. It has recently become associated with the unrelated vulgarity jack off and is accordingly used less frequently than it once was.

3. Sociolinguists have typically not expected African Americans to share local whites' speech features or participate in local whites' patterns of language change. Thus, interactions between African Americans' and whites' speech and ideas about speech have largely escaped scholarly notice. Eberhardt (2008) shows, however, that Pittsburgh African Americans do in fact share one phonological feature (the merger of the low back vowels $/ a /$ and $/ \partial /$ ) with white Pittsburghers and not with African Americans elsewhere, and my research shows that Pittsburgh African Americans use a number of lexical items common to local whites but not to African Americans in other cities.

4. I do not mean to suggest that all urban dialects are initially enregistered as working-class, simply that this is what happened in Pittsburgh.

5. In this, Pittsburghese shirts are very different from the sports-team shirts they are usually sold with. Unlicensed uses of logos and other design elements of sports T-shirts can result in legal action by the national sports federations.

\section{REFERENCES}

Agha, Asif. 2003. "The Social Life of Cultural Value." Language and Communication 23: 231-73.

- 2007. Language and Social Relations. New York: Cambridge Univ. Press.

Anderson, Benedict. 1991. Imagined Communities: Reflections on the Origin and Spread of Nationalism. Rev. and extended ed. London: Verso.

Appadurai, Arjun. 1986. "Commodities and the Politics of Value." In The Social Life of Things: Commodities in Cultural Perspective, ed. Arjun Appadurai, 3-63. Cambridge: Cambridge Univ. Press.

Bendix, Regina. 1988. "Folklorism: The Challenge of a Concept." International Folklore Review 6: $5^{-1} 5^{\text {. }}$ 
Bucholtz, Mary. 1999. "Purchasing Power: The Gender and Class Imaginary on the Shopping Channel." In Reinventing Identities: The Gendered Self in Discourse, ed. Mary Bucholtz, A. C. Liang, and Laurel A. Sutton, 348-368. New York: Oxford Univ. Press.

- 2008. "Shop Talk: Branding, Consumption and Gender in American MiddleClass Youth Interaction." In Words, Worlds, and Material Girls: Language, Gender, Globalization, ed. Bonnie S. McElhinny, 371-402. Berlin: Mouton de Gruyter.

Cameron, Deborah. 200o. "Styling the Worker: Gender and the Commodification of Language in the Globalized Service Economy." Journal of Sociolinguistics 4: $323-47$.

Carver, Craig M. 1987. American Regional Dialects: A Word Geography. Ann Arbor: Univ. of Michigan Press.

Eberhardt, Maeve. 2008. "The Low-Back Merger in the Steel City: African American English in Pittsburgh." American Speech 83: 284-31 1.

Fairclough, Norman. 1992. Discourse and Social Change. Cambridge: Polity.

Gaudio, Rudolf P. 2003. "Coffeetalk: Starbucks ${ }^{\mathrm{TM}}$ and the Commercialization of Casual Conversation." Language in Society 32: 659-91.

Hall, Kira. 1995. "Lip Service on the Fantasy Lines." In Gender Articulated: Language and the Socially Constructed Self, ed. Kira Hall and Mary Bucholtz, 183-216 . New York: Routledge, Hall.

Heller, Monica. 2003. "Globalization, the New Economy, and the Commodification of Language and Identity." Journal of Sociolinguistics 7: 473-92.

Johnstone, Barbara. 2007. "Linking Identity and Dialect through Stancetaking." In Stancetaking in Discourse: Subjectivity, Evaluation, Interaction, ed. Robert Englebretson, 49-68. Amsterdam: Benjamins.

—. Forthcoming. "Identity and the Place of Language." In Identities through Language, ed. Carmen Llamas and Dominic Watt. Edinburgh: Edinburgh Univ. Press.

Johnstone, Barbara, Jennifer Andrus, and Andrew E. Danielson. 20o6. "Mobility, Indexicality, and the Enregisterment of 'Pittsburghese.'” Journal of English Linguistics 34: 77-104.

Kelly, Marjorie. 2003. "Projecting an Image and Expressing Identity: T-shirts in Hawaii." Fashion Theory 7: 191-212.

Kretzschmar, William A., Jr. 2005. Linguistic Atlas Projects. http://us.english.uga $. \mathrm{edu} /$.

Labov, William, Sharon Ash, and Charles Boberg. 2006. Atlas of North American English: Phonetics, Phonology and Sound Change. Berlin: Mouton de Gruyter.

McCool, Sam. 1982. Sam McCool's New Pittsburghese: How to Speak Like a Pittsburgher. Pittsburgh, Penn.: Hayford.

Miller, Sylva Jean. 2002. "Phish Phan Pholklore: Identity and Community through Commodities in the Phish Parking Lot Scene." Midwestern Folklore 28: 42-6o.

Ochs, Elinor. 1992. "Indexing Gender." In Rethinking Context: Language as an Interactive Phenomenon, ed. Alessandro Duranti and Charles Goodwin, 335-58. New York: Cambridge Univ. Press. 
Silverstein, Michael. 1993. "Metapragmatic Discourse and Metapragmatic Function." In Reflexive Language: Reported Speech and Metapragmatics, ed.John A. Lucy, 33-58. Cambridge: Cambridge Univ. Press.

- 2003. "Indexical Order and the Dialectics of Sociolinguistic Life." Language and Communication 23: 193-229.

Symes, Colin. 1987. "Keeping Abreast with the Times: Towards an Iconography of T-Shirts." Studies in Popular Culture 12: 87-100.

Tan, Peter K. W., and Rani Rubdy, eds. 2008. Language as Commodity: Global Structures, Local Marketplaces. London: Continuum. 